OPEN ACCESS

Edited by:

Lino Nobili,

Università di Genova, Italy

Reviewed by:

Etienne Challet,

Centre National de la Recherche Scientifique (CNRS), France

Satvinder Kaur,

Beth Israel Deaconess Medical Center and Harvard Medical School, United States

*Correspondence: Junchao Zhu

zhujunchao1@hotmail.com

tThese authors have contributed equally to this work

Specialty section: This article was submitted to Sleep Disorders,

a section of the journal

Frontiers in Neurology

Received: 06 March 2020 Accepted: 28 May 2020

Published: 08 July 2020

Citation:

Luo M, Song B and Zhu J (2020) Sleep Disturbances After General Anesthesia: Current Perspectives.

Front. Neurol. 11:629.

doi: 10.3389/fneur.2020.00629

\section{Sleep Disturbances After General Anesthesia: Current Perspectives}

\author{
Man Luo ${ }^{1 \dagger}$, Bijia Song ${ }^{1,2 t}$ and Junchao Zhu ${ }^{1 *}$ \\ ${ }^{1}$ Department of Anesthesiology, Shengjing Hospital of China Medical University, Shenyang, China, ${ }^{2}$ Department of \\ Anesthesiology, Friendship Hospital of Capital Medical University, Beijing, China
}

The purpose of this article is to review (1) sleep mechanism under general anesthesia, harmful effects of postoperative sleep disturbances; (2) risk factors associated with postoperative sleep disturbances; (3) measures to prevent and improve postoperative sleep disturbances. General anesthesia changes the postoperative sleep structure especially in elderly patients after major surgery and results in a high incidence rate of sleep disturbances. Sleep disturbances produce harmful effects on postoperative patients and lead to a higher risk of delirium, more cardiovascular events, and poorer recovery. Some researchers do propose non-pharmacological treatments such as attention to environmental and psychological factors, application of electroacupuncture (EA) technology and pharmacological treatments are helpful, but larger high-quality clinical trials with longer following-up are needed to further investigate the efficacy and safety.

Keywords: general anesthesia, sleep, sleep disturbance, adverse effects, therapy

\section{INTRODUCTION}

General anesthesia is a medically induced state of low reactivity consciousness (1). Given the agent-specific clinical differences, general anesthesia is not considered a unitary state but rather an aggregate of the following discrete clinical endpoints: hypnosis (unawareness of one's environment), analgesia (lack of pain sensitivity), amnesia (lack of memory), and immobility after surgical stimulation (2). Current studies have revealed that sleep disturbances frequently occur in patients after surgery under general anesthesia. Postoperative sleep disturbances are not only one of the manifestations of postoperative brain dysfunction (3), but also can induce postoperative fatigue, metabolic disorders, hypertension, cerebrovascular, and cardiovascular disease. Besides, it is considered an important risk factor for delirium development (4). Here we reviewed pieces of evidence regarding sleep mechanism under general anesthesia, sleep rhythm disorders, risk factors, and treatments of postoperative sleep disturbances.

\section{SLEEP MECHANISM AND CIRCADIAN RHYTHM UNDER GENERAL ANESTHESIA}

The spontaneous sleep-wake cycle is repeated every $24 \mathrm{~h}$ in the normal population (5). Sleep includes 5 stages, stages 1-4 [non-rapid eye movement (NREM), also called slow-wave sleep (SWS) phase] and stage 5 [rapid eye movement (REM) phase]. The sleep cycle is composed of NREM, REM, and wake phases, and there are 3-5 sleep cycles each day and night. The loss of consciousness induced by anesthetics is similar to NREM sleep according to the cerebral blood flow imaging studies $(6,7)$. General anesthesia is a drug-induced state of loss of consciousness, 
which is a non-physiological process that is not easily affected by the surrounding environment. It is mainly controlled by the amount and time of anesthetic administration (8). Jiang-Xie et al. (9) found the hypothalamic neuron core group in the supraoptic nucleus and its vicinity was mainly composed of neuroendocrine cells, which were persistently and commonly activated by multiple classes of general anesthesia drug. The hypothalamus involved in sleep regulation may be the target of general anesthetics (10). The ventrolateral preoptic nucleus (VLPO) of the hypothalamus is a key area for sleep promotion that is mainly composed of GABAergic neurons. Anesthetic drugs, including propofol, and thiopental sodium, enhance GABA neuronal activity in the VLPO. These findings identified a common neural substrate underlying diverse general anesthesia drugs and natural sleep. General anesthetics induce sedation, hypnosis, and loss of consciousness by activating sleep-promoting nerve nuclei and inhibiting wake-promoting nerve nuclei in the brain (11). General anesthesia disrupts sleep/wake cycle and other circadian rhythms such as those of body temperature and melatonin secretion (12). There is some experimental evidence indicating that general anesthesia alters the molecular clock that relies on clock genes such as Period (Per), Cryptochromes (Cry), Clock and Bma1, in particular in the master clock in the suprachiasmatic nuclei $(13,14)$. Such a master clock controls the timing of sleep-wake cycle and circadian rhythm of body temperature and melatonin secretion, among others. Thus, a parsimonious hypothesis to explain altered sleep-wake cycle after general anesthesia involves an impaired function of the master clock $(15,16)$. Furthermore, Cronin et al. demonstrated that general anesthesia by inhalation (unspecified anesthetic) for gynecology surgical procedures decreased nocturnal melatonin levels on the first postoperative night compared to the second and third postoperative nights and returned to baseline levels only after the third night $(17,18)$. A study by Guo et al. on adults anesthetized for cardiac surgery (propofol-fentanyl) reported decreased melatonin secretion on the night after anesthesia administration (19).

\section{THE POSSIBLE MECHANISMS OF ANESTHETICS AND ANALGESICS}

\section{The Effect of Anesthetics and Analgesics on Postoperative Sleep}

Anesthetic-induced loss of consciousness (also termed hypnosis) could arise from anesthetic actions on the neuronal circuits regulating arousal (20). Hemmings Hugh et al. (21) reported that anesthetic drugs act at several neural sites to interrupt the connection between the cortex and its linking subcortical tissues. Opioids might cause postoperative sleep disturbances on healthy individuals and opioid addicts, which are characterized by reduced SWS, dose-dependent REM suppression, and awakenings or arousals during sleep through exerting control over various biological systems $(22,23)$. Furthermore, the anesthetic agent choice may affect changes in sleep architecture. Exposure of infants to propofol and remifentanil anesthesia has been shown to generally impair postoperative sleep quality (24).
Studies on mice and adult humans have shown that exposure to volatile general anesthetics, including sevoflurane, isoflurane, and halothane, might cause short-term sleep disturbances and fragmentation. In humans, isoflurane anesthesia alone without surgery was shown to have no effect on REM or NREM sleep except for a shift from deeper (III and IV) to lighter (I and II) NREM sleep stages $(25,26)$. Pick et al. (27) found that sevoflurane inhalation can induce REM sleep deficits, delayed REM sleep recovery, and decreased latency to REM sleep, without affecting wakefulness or non-REM sleep.

\section{The Effect of Anesthetics and Analgesics on Immune Response and Cardiovascular Events}

Opioids such as morphine may inhibit the activity of NK cell and the differentiation of $\mathrm{T}$ cell. It may also promote lymphocyte apoptosis and reduce the expression of toll-like receptor 4 (TLR4) on macrophages $(28,29)$. Fentanyl and sufentanil may decrease NK cell activity, however increase regulatory $\mathrm{T}$ cells (30). The side-effects of propofol are hemodynamic instability and cardiovascular complications such as hypotension, which may due to the reduced preload and afterload of the heart. Riznyk et al. found that the hypotension caused by propofol is not synchronized with heart's compensatory responses and would be intensified by high doses and high-speed injection of the drug $(31,32)$. The accumulated data showed that propofol inhibited the functions of neutrophils, monocytes, and macrophages in innate immunity, but not NK cells and lymphocytes. Propofol has anti-inflammatory and antioxidant effects by inhibiting innate immunity (33). Sevoflurane is one of the widely used volatile anesthetics, which may affect the immune response by increasing the levels of pro-tumorigenic cytokines and MMPs $(34,35)$. Similarly, isoflurane may induce apoptosis of $\mathrm{T}$ and B lymphocytes, attenuate NK cell activity, and decrease the Th1/Th2 ratio (36).

\section{FUNCTIONAL CHANGES AFTER POSTOPERATIVE SLEEP DISTURBANCES}

Postoperative sleep disturbances are featured by insomnia, hypersomnia and narcolepsy, changed sleep structure and increased frequency waking $(37,38)$. Postoperative sleep disturbances caused by general anesthesia might increase the incidence of postoperative complications such as postoperative fatigue, severe anxiety and depression, delirium $(39,40)$, and even severe stroke [(41); Figure 1].

\section{Effect of Postoperative Sleep Disturbances on Melatonin}

Melatonin (N-acetyl-5-methoxytryptamine) is a methoxyindole synthesized and secreted principally by the pineal gland at night under normal light/dark conditions, which is an important physiological sleep regulator in diurnal species including humans with effects on sedation, hypnotization, and regulation of the sleep-wake cycle (42). There is a sharp increase in sleep propensity at night usually occurring $2 \mathrm{~h}$ after the onset of 


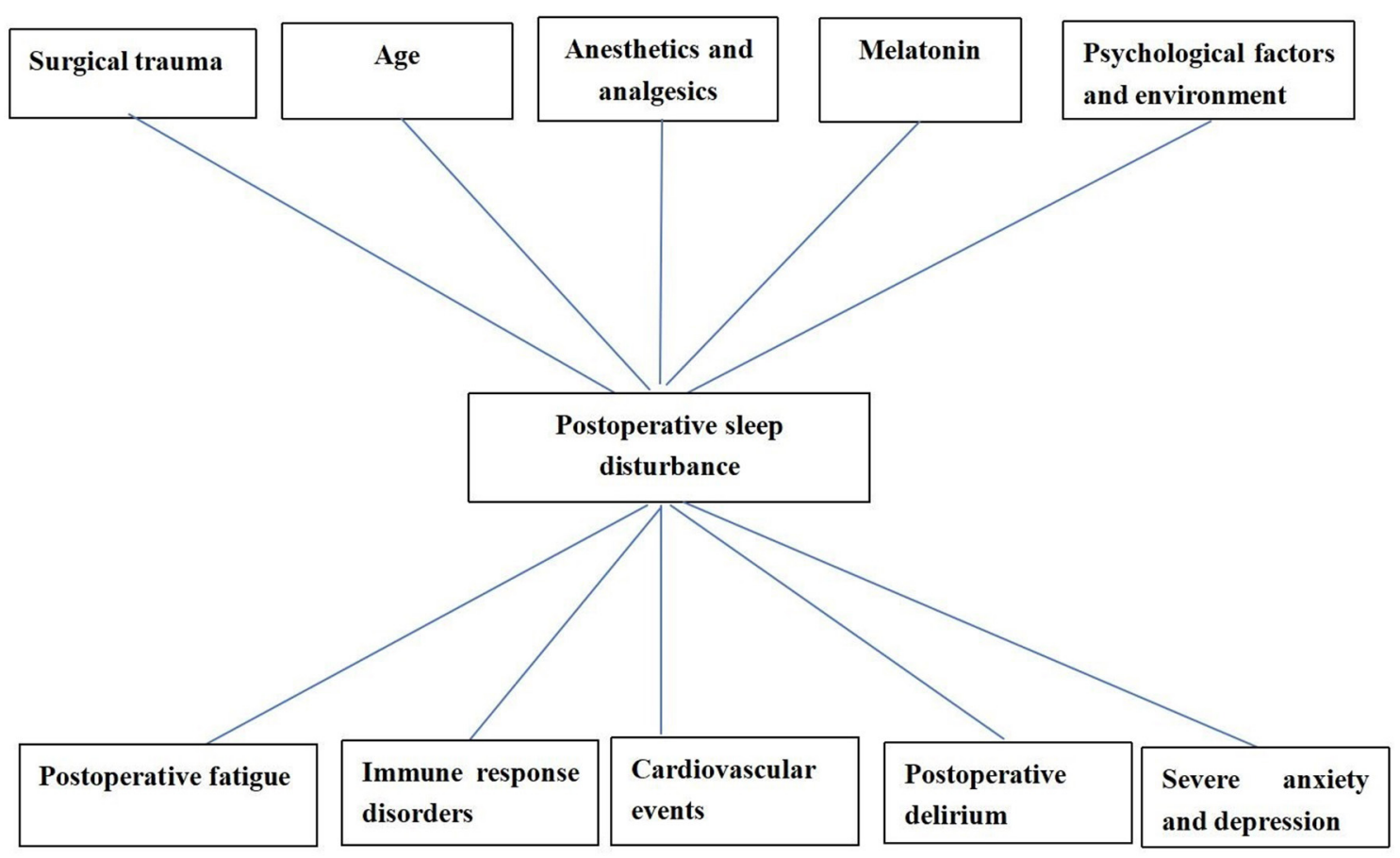

FIGURE 1 | The common acupoints in the treatment of sleep disorders.

endogenous melatonin production in humans (43). Studies confirmed that large surgical traumatic stimulus and general anesthetics usually caused postoperative sleep disturbances and a higher probability of postoperative cognitive impairment (44-46). Fadayomi et al. (4) found that sleep disturbances were modifiable risk factors for postoperative delirium. Patients who had sleep disturbances before surgery were more likely to have postoperative delirium. If severe, it may result in probable mental changes [e.g., inattention, hallucination, seclusiveness, irritability, and even aggressiveness; (47)]. The degree of cognitive impairment caused by sleep disorder may range from subtle derangements in attention, reason, clarity of thought, and capacity for decision making, to confusion and delirium (48). Mehrnoush et al. (49) found that sleep disturbance was common among patients undergoing coronary artery bypass graft surgery (CABG), especially during the first week of the postoperative period, which was partly due to disturbed melatonin secretion in the perioperative period. It seemed that modifying the melatonin level by adding exogenous melatonin to the natural circadian hormone could result in the amelioration of sleep disturbance.

\section{Effect of Postoperative Sleep Disturbances on Immune Response and Cardiovascular Events}

Sleep is thought to be an important regulator of the immune response. Sleep can regulate the function of the immune system by inducing changes in the sympathetic nervous system and hypothalamus-pituitary-adrenal axis. The circadian rhythms of hormones such as cortisol, adrenaline, and melatonin contribute to the different activities of the immune system. Sleep and immune factors are related and coordinated by inflammatory factors (tumor necrosis factors and interleukin) (50, 51). The immune system is under a bidirectional relationship with sleep. Sleep generally improve immune functions and may reduce the parameters that are involved in the rejection process. Sleep deprivation may weaken immunity and increases organism susceptibility to infection (52). These situations should adapt to the changes in sleep patterns and other parameters during the immune response to infections to which the organism is continuously exposed (53). Sleep disturbances are related to an increased risk of cardiovascular and cerebrovascular diseases (54). Insomnia may cause the development of cardiovascular disease and may increase the incidence rate of stroke and affect the poststroke outcome (55). And the treatment of sleep disturbances may improve sleep-related symptoms and benefit the long-term outcomes (56). There is also a direct correlation between the hepatic clock and Bmall genes and the occurrence and development of cardiovascular and cerebrovascular diseases (57). These findings have shown that circadian rhythm disturbances, which are due to the interference of general anesthetics in the biological clock genes, result in the occurrence of cardiovascular and cerebrovascular diseases via several mechanisms, thus influencing the recovery of patients.

\section{RISK FACTORS ASSOCIATED WITH POSTOPERATIVE SLEEP DISTURBANCES}

There are a variety of complicated influential factors for postoperative sleep disturbances, such as patient age, surgical 
trauma, anesthetic mode, postoperative pain, postoperative complications, anesthetics and analgesics, environment, and psychological factors [(39, 58); Figure 2]. People with preoperative sleep disturbances are more likely to have postoperative sleep disturbances (59). People with some diseases [such as obstructive sleep apnea (OSA), AttentionDeficit/Hyperactivity Disorder (ADHD), polycystic ovary syndrome (PCOS) often have sleep disturbances, which need our attention (60-62)]. Some studies have shown that sleep disturbances are common maladies associated with human age. The elderly are more likely to have sleep disturbances (63). The reason is that the elderly have significantly lower levels of melatonin (urine 6-methoxymelatonin) than younger people $(64,65)$. Further, elderly patients are a group of diminishing physiological reserves and increasing prevalence of frailty, which may affect the brain and central nervous system, leading to postoperative sleep disturbances (66). Studies indicated that the greatest incidence of sleep disturbances was found after major surgical procedures. The duration of the operative procedure was related to the duration of postoperative sleep disturbance, probably as a result of more extensive surgical trauma and a serious condition for the patients $(67,68)$.

This is associated with the inflammatory reaction, sympathetic nervous excitement, and endocrine disturbance caused by surgical trauma, the increase of cytokines (IL-1, IL-6, and TNF- $\alpha$ ), cortisol and catecholamine $(67,69)$, and the decrease of melatonin level in the body after surgery (17). Different surgical procedures cause different complications, which have different effects on sleep quality (70). Laparoscopic surgery is associated with a reduced inflammatory response, and classic endocrine metabolic responses are either less influenced or not affected at all as compared with similar open surgeries (71). After laparoscopic cholecystectomy, only a slight change in SWS was seen on the 1st night after surgery and there was no change in REM sleep. These findings confirmed that the magnitude of the surgical trauma and/or postoperative opioid administration might be key pathogenic factors in postoperative sleep disturbances (67). Studies have shown that in general surgical and orthopedic wards, postoperative pain is the most significant and detrimental factor of postoperative sleep disturbances, which may interact with each other (72). Pain can prolong the sleep latency and reduce the total sleep time, while sleep disturbances can increase pain sensitivity and decrease the pain threshold; even the pain severity in the next day can be predicted with the postoperative sleep quality (73). The impact of psychological factors on postoperative sleep disturbances is also substantial. Postoperative patients usually feel anxious and fearful and may enter a prolonged depressed and worried state owing to the financial burden and image change, which seriously influences their sleep and rehabilitation (74). Additional factors affecting the sleep of patients are postoperative environmental change, insufficient beds, noise, and lights in the ward, electrocardiographic monitoring of vital signs, nighttime treatment and nursing checks, alarms caused by machine faults, postoperative diets, and stimulation from the urinary catheter (72).

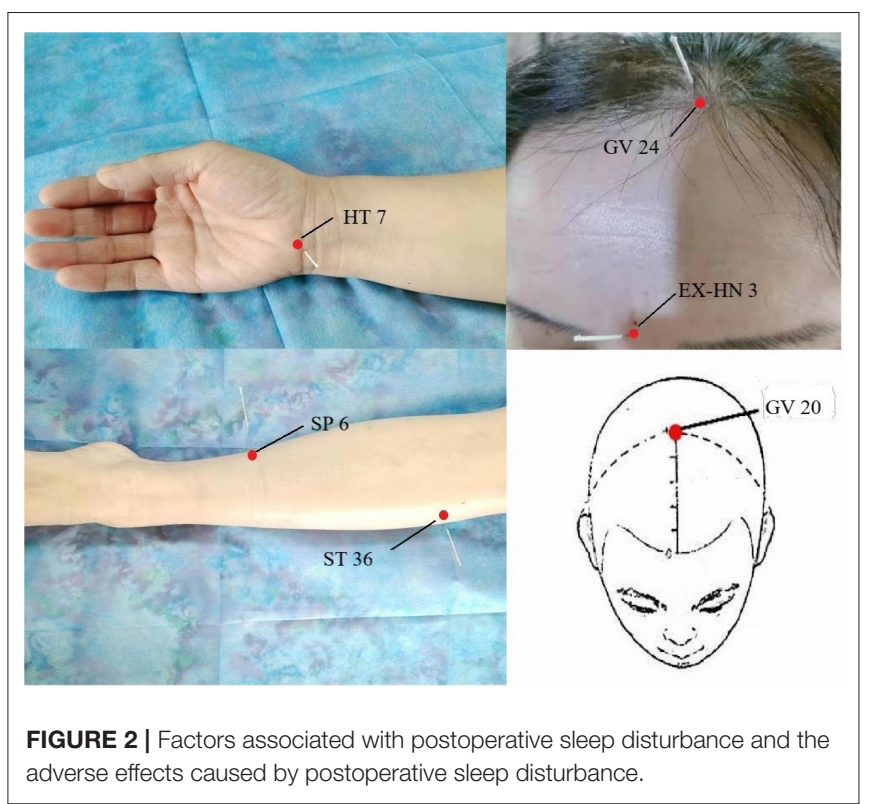

TABLE 1 | Treatment of postoperative sleep disturbance.

\begin{tabular}{ll}
\hline Non-pharmacological & Pharmacological \\
\hline Environment improvement & Sedatives \\
Reducing nursing activities & Benzodiazepines \\
Earplugs and eye-mask & Zolpidem \\
Surgical skills improvement & Melatonin \\
Reducing tissue injury & Analgesics \\
Psychological counseling & Opioids \\
Acupuncture & NSAIDs \\
Single acupuncture: sishencong (EX-HN1) & \\
Multiple acupuncture: baihui (GV20) yintang (GV29) & \\
baihui (GV20) shenting (GV24) & \\
neiguan (PC6) sanyinjiao (SP6) shenting (GV24) &
\end{tabular}

\section{MEASURES TO PREVENT AND IMPROVE POSTOPERATIVE SLEEP DISTURBANCES}

In the following section, we discussed treatment differentiating between non-pharmacological and pharmacological approaches (Table 1).

\section{Non-drug Therapy}

The trauma and duration of surgeries both affected the sleep rhythm, so the severity of postoperative sleep disturbances could be effectively decreased by improving the surgical technologies and reducing tissue injury (75). The individualized anesthetic plan is recommended and local anesthesia is preferable to general anesthesia in reducing postoperative sleep disturbance (76). For patients with sleep disturbances caused by psychological factors, it is necessary to carry out health education before 
surgery to reduce the influence of psychological factors on sleep after surgery. Studies have shown that psychological counseling can reduce the occurrence of postoperative sleep disturbances (74). The effective measures (reducing nursing activities, using earplugs and eye masks, etc.) may minimize the impact of environmental factors on sleep (77). The efficacy of electroacupuncture alone or combined with drugs in the treatment of sleep disturbances is better than that of drugs alone and more secure (78). The common acupoints in the treatment of sleep disturbances were presented in Figure 2. Garland et al. (79) made a randomized controlled trial involving 58 breast cancer survivors experiencing bothersome hot flashes at least two times per day. Participants were randomly assigned to receive 8 weeks of electroacupuncture or daily gabapentin (total dose of $900 \mathrm{mg} / \mathrm{d}$ ). By the end of treatment at week 8 , the mean reduction in the Pittsburgh Sleep Quality Index (PSQI) total score was significantly greater in the electroacupuncture group than the gabapentin group. The electroacupuncture group had improved sleep duration and better sleep quality compared with baseline. The study found that electroacupuncture stimulation at bilateral Zusanli (ST36) and san yin jiao (PC6) significantly deepened the sedation level of general anesthesia in patients with propofol target controlled infusion (TCI), and provided significant delayed sedation effects (80). The combination of electroacupuncture [Shenting (GV24) and yintang (EX-HN3)] and dexmedetomidine injection are more effective than those of dexmedetomidine injection alone. Electroacupuncture appears to reduce the dose of sedative drugs required in critically ill patients, without any obvious adverse severe action, and improve the safety of treatment $(81,82)$. Different acupoints improve sleep through different mechanisms in electroacupuncture treatment. For example, acupuncture at baihui (GV20) for insomnia and related symptoms may be sedative by reducing the excitability of the cerebral cortex (83). Electroacupuncture at (shenmen) HT7 and (sanyinjiao) SP6 have a positive effect in improving insomnia and insomniainduced fatigue in insomnia rats, which may be associated with its effects in up-regulating the levels of neurotransmitters [e.g., 5HT and 5-HIAA; (84)]. Chiu et al. (85) found that acupuncture caused an increase in E2 level and a decrease in folliclestimulating hormone (FSH) and luteinizing hormone (LH) levels, and the change of these levels was positively correlated with the improvement of sleep disturbances; meanwhile, acupuncture relieved sleep disturbances by improving the frequency and severity of hot flash. Electroacupuncture has significant analgesic and sedative effects, relieving anxiety, and reducing the risk factors of postoperative sleep disturbances $(86,87)$.

\section{Drug Therapy}

For the patients who need to use drugs to relieve the postoperative sleep disturbances, zolpidem is a high-affinity positive modulator of $\omega 1$ GABAA receptors which can be used to improve sleep quality and fatigue one night before and one night after surgery $(88,89)$.
Melatonin as a methoxyindole synthesized and secreted principally by the pineal gland at night under normal light/dark conditions is also an effective drug for the treatment of circadian sleep-wakefulness disorder (5). The application of melatonin before and after surgery can improve sleep quality, and it can also produce a sedative effect in the early postoperative period without obvious side effects $(90,91)$. In addition, melatonin may be considered an effective alternative for benzodiazepines in the management of postoperative sleep disturbances (92). There is also some evidence in the literature that supports the use of melatonin in the treatment of postoperative delirium. The administration of exogenous melatonin may prevent delirium from improving postoperative sleep deprivation. The mechanism is explained under the "tryptophan theory" that the administration of exogenous melatonin might prevent delirium by inhibiting the breakthrough of both serotonin and tryptophan by the feedback mechanism (93). Clinical trials found that using dexmedetomidine intraoperatively could improve sedative effects, reduce the incidence of postoperative delirium and promote postoperative sleep quality $(94,95)$. Weber et al. showed that $\alpha 2$ adrenergic receptor agonist medications might closely produce neural activity similar to non-REM sleep (96). Dexmedetomidine may reduce the duration of mechanical ventilation, ICU stay and hospital stay among patients in the intensive care unit (ICU) (97) and may also reduce the postoperative 30-day mortality, postoperative delirium, atrial fibrillation, and cardiac arrest in patients underwent cardiac surgery (98). Though sedatives such as benzodiazepines and " $\mathrm{Z}$ drugs" (zaleplon, zolpidem, and zopiclone) may improve sleep, however they may also contribute to confusion and delirium especially in the elderly (99). The relationship between sleep and pain is reciprocal, poor sleep also raises the sensitivity of pain. Previous study demonstrated that opioids could improve postoperative sleep quality, duration, or efficiency. Opioids could also cause sleep disturbances which lead to hyperalgesia (100). Opioids have been widely used for analgesic effect in the operation. It also pose great challenges to the clinicians due to unfavorable side effect profiles, abuse and tolerance (101). Ketorolac tromethamine (Toradol), a non-steroidal anti-inflammatory drug, is used frequently due to its success in relieving postoperative pain and reducing the need for narcotics (102). Recent study showed that the non-steroidal antiinflammatory drugs (NSAIDs) are not associated with increased postoperative bleeding and have fewer complications than opioids (103). When patients receive nocturnal sedative/hypnotic therapy for a long time, the sedative treatment should be reconstituted postoperatively as soon as possible to avoid postoperative sleep disturbance caused by the withdrawal of drugs (104).

\section{CONCLUSION}

Postoperative sleep disturbances have severe impacts on cognition, pain perception, altered circadian rhythm, 
psychomotor function, cardiovascular outcomes, metabolic function, catabolic responses, and inflammation. The relationship between general anesthesia and postoperative sleep disturbances is still unclear. It is advantageous to identify patients with preexisting sleep disturbances as they are associated with a high risk of postoperative sleep disturbances. Though pharmacological treatments are helpful, they may also present some adverse effects. Nonpharmacological treatments such as electroacupuncture technology need more high-quality clinical trials with longer following-up to further investigated the efficacy.

\section{REFERENCES}

1. Kushikata T, Yosmda H, Yasuda T, Tose R, Hirota K, Matsuki A. Sleep and anesthesia-part 2, on the relationship between sleep and general anesthesia. Masui. (2007) 56:1148-54.

2. Prys-Roberts C. Anaesthesia: a practical or impractical construct? $\mathrm{Br} \mathrm{J}$ Anaesth. (1987) 59:1341-5. doi: 10.1093/bja/59.11.1341

3. Horner RL, Peever JH. Brain circuitry controlling sleep and wakefulness. Continuum. (2017) 23:955-72. doi: 10.1212/CON.0000000000000495

4. Fadayomi AB, Ibala R, Bilotta F, Westover MB, Akeju O. A systematic review and meta-analysis examining the impact of sleep disturbance on postoperative delirium. Crit Care Med. (2018) 46:e1204-12. doi: 10.1097/CCM.0000000000003400

5. Wichniak A, Jankowski KS, Skalski M, Skwarło-Sonta K, Zawilska JB, Zarowski $\mathrm{M}$, et al. Treatment guidelines for circadian rhythm sleepwake disorders of the polish sleep research society and the section of biological psychiatry of the polish psychiatric association. Part I physiology, assessment, and therapeutic methods. Psychiatria Polska. (2017) 51:793814. doi: 10.12740/PP/OnlineFirst/66810

6. Nelson LE, Franks NP, Maze M. Rested and refreshed after anesthesia? Overlapping neurobiological mechanisms of sleep and anesthesia. Anesthesiology. (2004) 100:1341-2. doi: 10.1097/00000542-200406000-00003

7. Alkire MT, Hudetz AG, Tononi G. Consciousness and anesthesia. Science. (2008) 322:876-80. doi: 10.1126/science.1149213

8. Bonhomme V, Staquet C, Montupil J, Defresne A, Kirsch M, Martial C, et al. General anesthesia: a probe to explore consciousness. Front Syst Neurosci. (2019) 13:36. doi: 10.3389/fnsys.2019.00036

9. Jiang-Xie LF, Yin L, Zhao S, Prevosto V, Han BX, Dzirasa K, et al. A common neuroendocrine substrate for diverse general anesthetics and sleep. Neuron. (2019) 102:1053-65. doi: 10.1016/j.neuron.2019.03.033

10. Fukuda S, Yasuda A, Lu Z, Takata J, Sawai A, Sento Y, et al. Effect sites of anesthetics in the central nervous system network-looking into the mechanisms for natural sleep and anesthesia. Masui. (2011) 60:544-58.

11. Mashour George A, Hudetz Anthony G. Bottom-up and top-down of general anesthetics modulate different dimensions of consciousness. Front Neural Circuits. (2017) 11:44. doi: 10.3389/fncir.2017.00044

12. Dispersyn G, Touitou Y, Coste O, Jouffroy L, Lleu JC, Challet E, et al. Desynchronization of daily rest-activity rhythm in the days following light propofol anesthesia for colonoscopy. Clin Pharmacol Ther. (2009) 85:515. doi: 10.1038/clpt.2008.179

13. Tian JX, Yin C, Chu SS, Ma ZL, Gu XP. Murine clock gene expression in the suprachiasmatic nuclei and peripheral blood mononuclear cells during the daily sleep-wake rhythm and after isoflurane anesthesia. Sleep Biolog Rhythm. (2015) 13:357-65. doi: 10.1111/sbr.12126

14. Buhr ED, Takahashi JS. Molecular components of the Mammalian circadian clock. Handb Exp Pharmacol. (2013) 217:3-27. doi: 10.1007/978-3-642-25950-0_1

15. Poulsen RC, Warman GR, Sleigh J, Ludin NM, Cheeseman JF. How does general anaesthesia affect the circadian clock? Sleep Med Rev. (2018) 37:3544. doi: 10.1016/j.smrv.2016.12.002

\section{AUTHOR CONTRIBUTIONS}

All authors contributed to drafting or revising the article, gave final approval of the version to be published, and agree to be accountable for all aspects of the work.

\section{FUNDING}

This present study was funded by the Key R\&D plan of Liaoning Provincial Science and Technology Department (Grant No. 2020JH2/10300123) and the Support Plan for Innovative Talents in Liaoning Higher Education Institution (Grant No. 201834).

16. Dispersyn G, Pain L, Challet E, Touitou Y. General anesthetics effects on circadian temporal structure: an update. Chronobiol Int. (2008) 25:83550. doi: 10.1080/07420520802551386

17. Cronin AJ, Keifer JC, Davies MF, King TS, Bixler EO. Melatonin secretion after surgery. Lancet. (2000) 356:12445. doi: 10.1016/S0140-6736(00)02795-1

18. Kärkelä J, Vakkuri O, Kaukinen S, Huang WQ, Pasanen M. The influence of anaesthesia and surgery on the circadian rhythm of melatonin. Acta Anaesthesiol Scand. (2002) 46:30-6. doi: 10.1034/j.1399-6576.2002. 460106.x

19. Guo XY, Luo AL, Ren HZ, Yie TH, Huang YG. Perioperative melatonin secretion rhythm in patients undergoing coronary artery bypass grafting surgery. Zhongguo Yi Xue Ke Xue Yuan Xue Bao. (2003) 25:594-8.

20. Mashour GA. Cognitive unbinding: a neuroscientific paradigm of general anesthesia and related states of unconsciousness. Neurosci Biobehav Rev. (2013) 37:2751-9. doi: 10.1016/j.neubiorev.2013.09.009

21. Hemmings HC Jr, Riegelhaupt PM, Kelz MB, Solt K, Eckenhoff RG, Orser $\mathrm{BA}$, et al. Towards a comprehensive understanding of anesthetic mechanisms of action: a decade of discovery. Trends Pharmacol Sci. (2019) 40:46481. doi: 10.1016/j.tips.2019.05.001

22. Dimsdale JE, Norman D, DeJardin D, Wallace MS. The effect of opioids on sleep architecture. J Clin Sleep Med. (2007) 3:33-6.

23. Shaw IR, Lavigne G, Mayer P, Choinière $M$. Acute intravenous administration of morphine perturbs sleep architecture in healthy pain-free young adults: a preliminary study. Sleep. (2005) 28:677-82. doi: 10.1093/sleep/28.6.677

24. Steinmetz J, Holm-Knudsen R, Eriksen K, Marxen D, Rasmussen LS. Quality differences in postoperative sleep between propofol-remifentanil and sevoflurane anesthesia in infants. Anesth Analg. (2007) 104:77983. doi: 10.1213/01.ane.0000255694.00651.5b

25. Moote CA, Knill RL. Isoflurane anesthesia causes a transient alteration in nocturnal sleep. Anesthesiology. (1988) 69:32731. doi: 10.1097/00000542-198809000-00007

26. Wren-Dail MA, Dauchy RT, Blask DE, Hill SM, Ooms TG, Dupepe LM, et al. Effect of isoflurane anesthesia on circadian metabolism and physiology in rats. Comp Med. (2017) 67:138-46.

27. Pick J, Chen Y, Moore JT, Sun Y, Wyner AJ, Friedman $\mathrm{EB}$, et al. Rapid eye movement sleep debt accrues in mice exposed to volatile anesthetics. Anesthesiology. (2011) 115:70212. doi: 10.1097/ALN.0b013e31822ddd72

28. Sacerdote P, Bianchi M, Gaspani L, Manfredi B, Maucione A, Terno $\mathrm{G}$, et al. The effects of tramadol and morphine on immune responses and pain after surgery in cancer patients. Anesth Analg. (2000) 90:14114. doi: 10.1097/00000539-200006000-00028

29. Gao M, Sun J, Jin W, Qian Y. Morphine, but not ketamine, decreases the ratio of Th1/Th2 in CD4-positive cells through T-bet and GATA3. Inflammation. (2012) 35:1069-77. doi: 10.1007/s10753-011-9413-6

30. Gong L, Qin Q, Zhou L, Ouyang W, Li Y, Wu Y, et al. Effects of fentanyl anesthesia and sufentanil anesthesia on regulatory $\mathrm{T}$ cells frequencies. Int J Clin Exp Pathol. (2014) 7:7708-16. 
31. Riznyk L, Fijałkowska M, Przesmycki K. Effects of thiopental and propofol on heart rate variability during fentanyl-based induction of general anesthesia. Pharmacol Rep. (2005) 57:128-34.

32. Morgan GE, Mikhail MS, Murray MJ. Clinical Anesthesiology. 4th ed. New York, NY: McGraw-Hill (2006). p. 200-2.

33. Qin JH, Zhang XR, He L, Zhu J, Ma QJ. Effect of sevoflurane and halothane anesthesia on cognitive function and immune function in young rats. Saudi J Biol Sci. (2018) 25:47-51. doi: 10.1016/j.sjbs.2016.08.002

34. Eger EI II, Eisenkraft JB, Weiskopf RB. Circulatory effects of inhaled anesthetics. In: The Pharmacology of Inhaled Anesthetics. 2nd ed. Chicago, IL: Healthcare Press (2003).

35. Deegan CA, Murray D, Doran P, Moriarty DC, Sessler DI, Mascha E, et al. Anesthetic technique and the cytokine and matrix metalloproteinase response to primary breast cancer surgery. Reg Anesth Pain Med. (2010) 35:490-5. doi: 10.1097/AAP.0b013e3181ef4d05

36. Tavare AN, Perry NJ, Benzonana LL, Takata M, Ma D. Cancer recurrence after surgery: direct and indirect effects of anesthetic agents. Int J Cancer. (2012) 130:1237-50. doi: 10.1002/ijc.26448

37. Knill RL, Moote CA, Skinner MI, Rose EA. Anesthesia with abdominal surgery leads to intense REM sleep during the first postoperative week. Anesthesiology. (1990) 73:52-61. doi: 10.1097/00000542-199007000-00009

38. Cavalcante A, Hofer R, Tippmann-Peikert M, Sprung J, Weingarten T. Perioperative risks of narcolepsy in patients undergoing general anesthesia: a case-control study. J Clin Anesthesia. (2017) 41:1205. doi: 10.1016/j.jclinane.2017.04.008

39. Haack M, Simpson N, Sethna N, Kaur S, Mullington J. Sleep deficiency and chronic pain: potential underlying mechanisms and clinical implications. Neuropsychopharmacology. (2020) 45:205-16. doi: 10.1038/s41386-019-0439-z

40. Mashour GA, Lipinski WJ, Matlen LB, Walker AJ, Turner AM, Schoen W, et al. Isoflurane anesthesia does not satisfy the homeostatic need for rapid eye movement sleep. Anesth Analg. (2010) 110:1283-9. doi: 10.1213/ANE.0b013e3181d3e861

41. Gögenur I, Wildschiøtz G, Rosenberg J. Circadian distribution of sleep phases after major abdominal surgery. Br J Anaesth. (2008) 100:459. doi: 10.1093/bja/aem340

42. Hardeland R, Poeggeler B, Srinivasan V, Trakht I, Pandi-Perumal SR, Cardinali DP. Melatonergic drugs in clinical practice. ArzneimittelForschung. (2008) 58:1-10. doi: 10.1055/s-0031-1296459

43. Zisapel N. Sleep and sleep disturbances: biological basis and clinical implications. Cell Mol Life Sci. (2007) 64:117486. doi: 10.1007/s00018-007-6529-9

44. Opperer M, Gernner P, Memtsoudis SG. Additives to local anesthetics for peripheral nerve blocks or local anesthesia: a review of the literature. Pain Manag. (2015) 5:117-28. doi: 10.2217/pmt.15.2

45. Oliveira DE, Tatsch-Dias M, Levandovski RM, Custódio de Souza IC, Gregianin Rocha M, Magno Fernandes PA, et al. The concept of the immunepineal axis tested in patients undergoing an abdominal hysterectomy. Neuroimmunomodulation. (2013) 20:205-12. doi: 10.1159/000347160

46. Ramos AR, Gardener H, Rundek T, Elkind MS, Boden-Albala B, Dong C, et al. Sleep disturbances and cognitive decline in the Northern Manhattan study. Neurology. (2016) 87:1511-6. doi: 10.1212/WNL.0000000000003168

47. Olson DM, Borel CO, Laskowitz DT, Moore DT, McConnell ES. Quiet time:a nursing intervention to promote sleep in neurocritical care units. Am J Crit Care. (2001) 10:74-8. doi: 10.4037/ajcc2001.10.2.74

48. Hajali V, Andersen ML, Negah SS, Sheibani V. Sex differences in sleep and sleep loss-induced cognitive deficits: the influence of gonadal hormones. Horm Behav. (2019) 108:50-61. doi: 10.1016/j.yhbeh.2018.12.013

49. Dianatkhah M, Ghaeli P, Hajhossein Talasaz A, Karimi A, Salehiomran A, Bina P, et al. Evaluating the potential effect of melatonin on the post-cardiac surgery sleep disorder. J Tehran Heart Cent. (2015) 10:122-8.

50. Rico-Rosillo MG, Vega-Robledo GB. Sueño y Sistema immune sleep and immune system. Rev Alert Mex. (2018) 65:16070. doi: 10.29262/ram.v65i2.359

51. Prather AA, V Vogelzang N, Penninx BW. Sleep duration, insomnia and markers of systemic inflammation: results from the Netherlands study of depression and anxiety(NESDA). J Psychiatr Res. (2015) 60:95102. doi: $10.1016 /$ j.jpsychires.2014.09.018
52. Francieli SR, Monica LA, Camila G, Leandro PA, José DL, Sergio T. Sleep influences the immune response and the rejection process alters sleep pattern: evidence from a skin allograft model in mice. Brain Behav Immun. (2017) 61:274-88. doi: 10.1016/j.bbi.2016.12.027

53. Ibarra-Coronado EG, Pantaleón-Martínez AM, Velazquéz-Moctezuma J, Prospéro-García O, Méndez-Díaz M, Pérez-Tapia M, et al. The bidirectional relationship between sleep and immunity against infections. J Immunol Res. (2016) 2015:678164-77. doi: 10.1155/2015/678164

54. Hepburn M, Bollu PC, French B, Sahota P. Sleep medicine: stroke and sleep. Mo Med. (2018) 115:527-32.

55. Wu MP, Lin HJ, Weng SF, Ho CH, Wang JJ, Hsu YW. Insomnia subtypes and the subsequent risks of stroke: report from a nationally representative cohort. Stroke. (2014) 45:1349-54. doi: 10.1161/STROKEAHA.113.003675

56. Mims KN, Kirsch D. Sleep and stroke. Sleep Med Clinics. (2016) 11:3951. doi: 10.1016/j.jsmc.2015.10.009

57. Anea CB, Zhang M, Stepp DW, Simkins GB, Reed G, Fulton DJ, et al. Vascular disease in mice with a dysfunctional circadian clock. Circulation. (2009) 119:1510-7. doi: 10.1161/CIRCULATIONAHA.108.827477

58. Vitiello MV, Moe KE, Prinz PN. Sleep complaints co-segregate with illness in older adults: clinical research by and informing epidemiological studies of sleep. Psychosom Res. (2002) 53:555-9. doi: 10.1016/s0022-3999(02)000435-x

59. Wang J-P, Lu S-F, Guo L-N, Ren C-G, Zhang Z-W. Poor preoperative sleep quality is a risk factor for severe postoperative pain after breast cancer surgery: a prospective cohort study. Medicine. (2019) 98:e17708. doi: 10.1097/MD.0000000000017708

60. Auckley D, Memtsoudis S. Unrecognized obstructive sleep apnea and postoperative cardiovascular complications: a wake-up call. JAMA. (2019) 321:1774-6. doi: 10.1001/jama.2019.4781

61. Wajszilber D, Santisteban JA, Gruber R. Sleep disorders in patients with ADHD: impact and management challenges. Nat Sci Sleep. (2018) 10:45380. doi: $10.2147 /$ NSS.S163074

62. Fernandez RC, Moore VM, Van Ryswyk EM, Varcoe TJ, Rodgers RJ, March WA, et al. Sleep disturbances in women with polycystic ovary syndrome: prevalence, pathophysiology, impact, and management strategies. Nat Sci Sleep. (2018) 10:45-64. doi: 10.2147/NSS.S127475

63. Paulose Jiffin K, Wang Chanung, O'Hara Bruce F, Cassone Vincent M. The effects of aging on sleep parameters in a healthy, melatonin-competent mouse model. Nat Sci Sleep. (2019) 11:113-21. doi: 10.2147/NSS.S214423

64. Alagiakrishnan K. Melatonin based therapies for delirium and dementia. Discov Med. (2016) 21:363-71.

65. Luboshitzky R, Shen-Orr Z, Tzischichinsky O, Maldonado M, Herer P, Lavie P. Actigraphic sleep-wake patterns and urinary 6-sulfatoxymelatonin excretion in patients with Alzheimer's disease. Chronobiol Int. (2001) 18:51324. doi: $10.1081 /$ CBI-100103973

66. Sterniczuk R, Rusak B, Rockwood K. Sleep disturbance in older ICU patients. Clin Interv Aging. (2014) 9:969-77. doi: 10.2147/CIA.S59927

67. Rosenberg-Adamsen S, Kehlet H, Dodds C, Rosenberg J. Postoperative sleep disturbances: mechanisms and clinical implications. Br J Anaesth. (1996) 76:552-9. doi: 10.1093/bja/76.4.552

68. Yilmaz H, Iskesen I. Follow up with objective and subjective tests of the sleep characteristics of patients after cardiac surgery. Circ J. (2007) 71:150610. doi: 10.1253 /circj. 71.1506

69. de Zambotti M, Covassin N, de Min Tona G, Sarlo M, Stegagno L. Sleep onset and cardiovascular activity in primary insomnia. J Sleep Res. (2011) 20:318-25. doi: 10.1111/j.1365-2869.2010.00871.x

70. Bonnet F, Marret E. Influence of anesthetic and analgesic techniques on outcome after surgery. $\mathrm{Br} J$ Anaesthesia. (2005) 95:52-8. doi: 10.1093/bja/aei038

71. Kehlet H, Nielsen HJ. Impact of laparoscopic surgery on stress responses, immunofunction, and risk of infectious complications. New Horiz. (1998) 6(Suppl.):S80-8.

72. Dolan R, Huh J, Tiwari N, Sproat T, Camilleri-Brennan J. A prospective analysis of sleep deprivation and disturbance in surgical patients. Ann Med Surg. (2016) 6:1-5. doi: 10.1016/j.amsu.2015.12.046

73. Lautenbacher S, Huber C, Kunz M, Parthum A, Weber PG, Griessinger $\mathrm{N}$, et al. Hypervigilance as a predictor of postoperative acute pain: its predictive potency compared with experimental pain sensitivity, 
cortisol reactivity, and affective state. Clin J Pain. (2009) 25:92100. doi: 10.1097/AJP.0b013e3181850dce

74. Scarpa M, Pinto E, Saraceni E, Cavallin F, Parotto M, Alfieri R, et al. Randomized clinical trial of psychological support and sleep adjuvant measures for postoperative sleep disturbance in patients undergoing oesophagectomy. Br J Surg. (2017) 104:1307-14. doi: 10.1002/bjs.10609

75. Gögenur I, Bisgaard T, Burgdorf S, van Someren E, Rosenberg J. Disturbances in the circadian pattern of activity and sleep after laparoscopic versus open abdominal surgery. Surg Endosc. (2009) 23:1026-31. doi: 10.1007/s00464-008-0112-9

76. Poyser T, Murugesan S, Smith A. Which patients benefit from regional anesthesia? Curr Opin Anaesthesiol. (2016) 29:620-5. doi: 10.1097/ACO.0000000000000363

77. Capezuti E, Sagha Zadeh R, Woody N, Basara A, Krieger AC. An integrative review of nonpharmacological interventions to improve sleep among adults with advanced serious illness. J Palliat Med. (2018) 21:70017. doi: $10.1089 / \mathrm{jpm} .2017 .0152$

78. Jin $\mathrm{H}$, Zhang $\mathrm{YT}$, Yang $\mathrm{Y}$, Wen LY, Wang JH, Xu HY, et al. Electroacupuncture facilitates the integration of neural stem cell-derived neural network with transected rat spinal cord. Stem cell Rep. (2019) 12:27489. doi: 10.1016/j.stemcr.2018.12.015

79. Garland SN, Xie SX, Li Q, Seluzicki C, Basal C, Mao JJ. Comparative effectiveness of electro-acupuncture versus gabapentin for sleep disturbances in breast cancer survivors with hot flashes: a randomized trial. Menopause. (2017) 24:517-23. doi: 10.1097/GME.0000000000000779

80. Chen Y, Zhang H, Tang Y, Shu J. Impact of bilateral ST36 and PC6 electroacupuncture on the depth of sedation in general anesthesia. Acupunct Med. (2015) 33:103-9. doi: 10.1136/acupmed-2014010594

81. Yu H-J, Xu X-Q, Xu S-A, Xu J, Cao W-Z. Analgesic and sedative effect of acupuncture combined with medicine on patients undergoing cardiac surgery. Zhongguo Zhong Xi Yi Jie He Za Zhi. (2016) 36:289-93.

82. Zheng $X$, Meng J-B, Fang Q. Electroacupuncture reduces the dose of midazolam monitored by the bispectral index in critically ill patients with mechanical ventilation: an exploratory study. Acupunct Med. (2012) 30:7884. doi: 10.1136/acupmed-2011-010095

83. Li J, Ran X, Cui C, Xiang C, Zhang A, Shen F. Instant sedative effect of acupuncture at GV20 on the frequency of electroencephalogram $\alpha$ and $\beta$ waves in a model of sleep deprivation. Exp Ther Med. (2018) 15:53538. doi: 10.3892/etm.2018.6123

84. Tang L, You F, Hu X, Li Y-F. Electroacupuncture improves insomnia by down-regulating peripheral benzodiazepine receptor expression in hippocampus, and up-regulating 5-HT, 5-HIAA, TNF- $\alpha$ and IL-1 $\beta$ contents in hypothalamus in insomnia rats. Acupunct Res. (2019) 44:5605. doi: $10.13702 / \mathrm{j} .1000-0607.180610$

85. Chiu HY, Hsieh YJ, Tsai PS. Acupuncture to reduce sleep disturbances in perimenopausal and postmenopausal women: a systematic review and meta-analysis. Obstetr Gynecol. (2016) 127:507-15. doi: 10.1097/AOG.0000000000001268

86. Amorim D, Amado J, Brito I, Fiuza SM, Amorim N, Costeira C, et al. Acupuncture and electroacupuncture for anxiety disorders: a systematic review of the clinical research. Complement Ther Clin Pract. (2018) 31:317. doi: 10.1016/j.ctcp.2018.01.008

87. Teoh AYB, Chong CCN, Leung WW, Chan SKC, Tse YK, Ng $\mathrm{EKW}$, et al. Electroacupuncture-reduced sedative and analgesic requirements for diagnostic EUS: a prospective, randomized, double-blinded, sham-controlled study. Gastrointest Endosc. (2018) 87:476-85. doi: 10.1016/j.gie.2017.07.029

88. Krenk L, Jennum P, Kehlet H. Postoperative sleep disturbances after zolpidem treatment in fast-track hip and knee replacement. J Clin Sleep Med. (2014) 10:321-6. doi: $10.5664 / j \mathrm{csm} .3540$
89. Che Has AT, Absalom N, van Nieuwenhuijzen PS, Clarkson AN, Ahring PK, Chebib M. Zolpidem is a potent stoichiometry-selective modulator of $\alpha 1 \beta 3$ GABAA receptors: evidence of a novel benzodiazepine site in the $\alpha 1-\alpha 1$ interface. Sci Rep. (2016) 6:28674. doi: 10.1038/srep28674

90. Borazan H, Tuncer S, Yalcin N, Erol A, Otelcioglu S. Effects of preoperative oral melatonin medication on postoperative analgesia, sleep quality, and sedation in patients undergoing elective prostatectomy: a randomized clinical trial. J Anesth. (2010) 24:155-60. doi: 10.1007/s00540-010-0891-8

91. Madsen MT, Hansen MV, Andersen LT, Hageman I, Rasmussen LS, Bokmand S, et al. Effect of melatonin on sleep in the perioperative period after breast cancer surgery: a randomized, double-blind, placebo-controlled trial. J Clin Sleep Med. (2016) 12:225-33. doi: 10.5664/jcsm.5490

92. Dumur J, Csajka C, Pavec O, Messaoudi S, Cretignier T, Gaspar F, et al. Which alternative to benzodiazepines, Z-pills and other hypnotics for aged people? Melatonin, valerian, or clomethiazole. Rev Med Suisse. (2018) 14:2018-23.

93. Lewis MC, Barnett SR. Postoperative delirium: the tryptophan dyregulation model. Med Hypotheses. (2004) 63:402-6. doi: 10.1016/j.mehy.2004.01.033

94. Su S, Ren C, Zhang H, Liu Z, Zhang Z. The opioid-sparing effect of perioperative DEX plus sufentanil infusion during neurosurgery: a retrospective study. Front Pharmacol. (2016) 7:407. doi: 10.3389/fphar.2016.00407

95. Mohta M, Kalra B, Sethi AK, Kaur N. Efficacy of DEX as an adjuvant in paravertebral block in breast cancer surgery. J Anesth. (2016) 30:25260. doi: 10.1007/s00540-015-2123-8

96. Weber F, Dan Y. Circuit-based interrogation of sleep control. Nature. (2016) 538:51-9. doi: 10.1038/nature19773

97. Shehabi Y, Howe BD, Bellomo R, Arabi YM, Bailey M, Bass FE, et al. Early sedation with dexmedetomidine in critically Ill patients. N Engl J Med. (2019) 380:2506-17. doi: 10.1056/NEJMoa1904710

98. Peng K, Ji F-H, Liu H-Y, Zhang J, Chen Q-C, Jiang Y-H. Effects of perioperative dexmedetomidine on postoperative mortality and morbidity: a systematic review and meta-analysis. Clin Ther. (2019) 41:13854. doi: 10.1016/j.clinthera.2018.10.022

99. Inouye SK, Westendorp RG, Saczynski JS. Delirium in elderly people. Lancet. (2014) 383:911-22. doi: 10.1016/S0140-6736(13)60688-1

100. Cheatle Martin D, Webster Lynn R. Opioid therapy and sleep disorders: risks and mitigation strategies. Pain Med. (2015) 16:S22-6. doi: 10.1111/pme.12910

101. Vadivelu N, Gowda AM, Urman RD, Jolly S, Kodumudi V, Maria M, et al. Ketorolac tromethamine - routes and clinical implications. Pain Pract. (2015) 15:175-93. doi: 10.1111/papr.12198

102. Nguyen BN, Barta RJ, Stewart CE, Heinrich CA. Toradol following breast surgery: is there an increased risk of hematoma? Plast Reconstr Surg. (2018) 141:814e-7e. doi: 10.1097/PRS.0000000000004361

103. Wick E C, Grant MC, Wu C L. Postoperative multimodal analgesia pain management with nonopioid analgesics and techniques. JAMA Surg. (2017) 152:691-7. doi: 10.1001/jamasurg.2017.0898

104. Busto U, Sellers EM, Naranjo CA, Cappell H, Sanchez-Craig M, Sykora K. Withdrawal reaction after long-term therapeutic use of benzodiazepines. $N$ Engl J Med. (1986) 315:854-9. doi: 10.1056/NEJM198610023151403

Conflict of Interest: The authors declare that the research was conducted in the absence of any commercial or financial relationships that could be construed as a potential conflict of interest.

Copyright $\odot 2020$ Luo, Song and Zhu. This is an open-access article distributed under the terms of the Creative Commons Attribution License (CC BY). The use, distribution or reproduction in other forums is permitted, provided the original author(s) and the copyright owner(s) are credited and that the original publication in this journal is cited, in accordance with accepted academic practice. No use, distribution or reproduction is permitted which does not comply with these terms. 